\title{
Epidemiology and burden of chronic constipation
}

\author{
Maria Ines Pinto Sanchez MD, Premysl Bercik MD
}

\author{
MI Pinto Sanchez, P Bercik. Epidemiology and burden of chronic \\ constipation. Can J Gastroenterol 2011;25(Suppl B):11B-15B.
}

\begin{abstract}
Chronic constipation is an important component of clinical gastroenterology practice worldwide. Based on the definition, either selfreported or using Rome criteria, chronic constipation can affect from $2 \%$ to $27 \%$ of the population. Constipation is physically and mentally troublesome for many patients, and can significantly interfere with their daily living and well-being. Although only a proportion of patients with constipation seek medical care, most of them use prescribed or over-the-counter medication to improve their condition. The health care costs of constipation are significant as evidenced by the hundreds of million dollars spent yearly on laxatives alone. Because constipation is more common in older patients and life expectancy is increasing, an increase in the prevalence of constipation is expected in the years to come, with the associated impact on quality of life and socioeconomic burden.
\end{abstract}

Key Words: Burden; Constipation; Epidemiology; Quality of life

Cunctional gastrointestinal diseases (FGIDs), including chronic Constipation (CC), are among the most frequent illnesses seen by gastroenterologists and account for up to one-half of patient care time (1). CC is a remarkably common and costly condition that can negatively impact the quality of life (QoL), and result in a major social and economic burden.

Constipation is a symptom-based disorder, and its definition is mainly subjective $(2,3)$. In this regard, there is often a lack of agreement between physician and patient's perception when defining constipation (4). To better characterize the condition, physicians conceive constipation objectively using defecation frequency, with a normal range of between three and 21 bowel movements per week (5). The definition of constipation has changed during the past decades, with the most recent Rome III criteria defining it as fewer than three bowel movements per week (Table 1). Conversely, patients are more concerned with ease of passage and consistency rather than stool frequency (6). Several studies have also shown that the perception of constipation was frequently related to straining or hard stools (7). Interestingly, many individuals with fewer than three bowel movements per week do not consider themselves to be constipated, while others embrace the popular belief that 'a bowel movement each day is necessary for good digestive health'. This individual perception of constipation is linked to millions of dollars spent on laxatives and stool softeners. In 1986, more than $\$ 200$ million was spent on nonprescription laxatives (8). Unfortunately, this situation has not improved and constipation-related expenses continue to increase (9). Furthermore, the annual estimated expenditure of $\$ 800$ million for laxatives in the United States (US) appears to be an underestimation because many patients purchase over-the-counter (OTC) preparations before escalating prescription medications (10).

Self-reported constipation is a subjective complaint influenced by cultural and social customs. It has been shown to be neither sensitive nor specific compared with symptom-based criteria, which makes actual prevalence difficult to evaluate $(4,11)$. Using the Rome criteria, a Canadian study (12) has shown that many patients

\author{
L'épidémiologie et le fardeau de la constipation \\ chronique
}

La constipation chronique est un élément important de la pratique clinique de la gastroentérologie dans le monde. D'après la définition, autoévaluée ou tirée des critères de Rome, la constipation chronique peut toucher de $2 \%$ à $27 \%$ de la population. La constipation est perturbante sur le plan physique et mental pour de nombreux patients et peut nuire considérablement à leur vie quotidienne et à leur bien-être. Même si seule une proportion de patients atteints de constipation demandent des soins médicaux, la plupart recourent à des médicaments prescrits ou en vente libre afin d'améliorer leur état. Les coûts de santé de la constipation sont importants, tel que le démontrent les centaines de millions de dollars dépensés chaque année pour l'achat des seuls laxatifs. Puisque la constipation est plus courante chez les patients plus âgés et que l'espérance de vie augmente, on prévoit une augmentation de la prévalence de constipation au cours des prochaines années, sans compter les effets connexes sur la qualité de vie et le fardeau socioéconomique.

complaining about constipation do not meet the Rome II diagnostic criteria for functional constipation. Nearly one-half fulfilled criteria for irritable bowel syndrome (IBS) and only $37.3 \%$ fit the definition for functional constipation. Almost $16 \%$ of patients met neither criteria, and these individuals may have suffered from other gastrointestinal (GI) diseases.

\section{PREVALENCE OF CC}

$\mathrm{CC}$ is a common complaint encountered by both primary care physicians and gastroenterologists, with prevalence estimates ranging from $1 \%$ to $8 \%$ of the North American population $(4,5,8,12)$. Although many population-based studies have evaluated the prevalence of constipation, the results are inconsistent because different criteria have been used. A recent historical cohort study of randomly selected subjects from Olmsted County (USA) evaluated 4176 subjects and reported a $16 \%$ overall prevalence of constipation (1). Another study estimated that constipation can affect up to $20 \%$ of the North American population (13).

In Canada, several studies have been performed using different definitions. In a survey-based study, Pare et al (14) found that the self-reported constipation rate was $27.2 \%$ considering a period of three months, and $38.6 \%$ considering 12 months. Applying the Rome I or II criteria for functional constipation to the same patients resulted in a prevalence of $16.7 \%$ and $14.9 \%$, respectively. These rates were markedly greater than the $4 \%$ to $5 \%$ prevalence rates observed in two large US national population-based surveys $(7,15)$, but similar to the $19.9 \%$ reported in middle-age residents of Olmsted County (16). In a more recent study using telephone interviews, Hunt et al (17) showed that chronic lower GI dysmotility and sensory symptoms were present in only $5.2 \%$ of the adult Canadian population. Finally, a systematic review (18) found the prevalence of CC in the US - assessed either by Rome criteria or self-reported - to range from $1.9 \%$ to $27.2 \%$, with an average of $14.8 \%$. In agreement with the previous studies, the authors concluded that variations in prevalence rate were due to the different methodology in collecting data.

The Farncombe Family Digestive Health Institute, Faculty of Health Sciences, McMaster University, Hamilton, Ontario

Correspondence: Dr Premysl Bercik, McMaster University Health Sciences Centre, 4W8, 1200 Main Street West, Hamilton, Ontario L8N 325.

Telephone 905-521-2100 ext 73495, fax 905-521-4958, e-mail bercikp@mcmaster.ca

Received for publication May 31, 2011. Accepted June 10, 2011 
TABLE 1

Definitions of functional constipation

\begin{tabular}{|c|c|c|c|c|}
\hline \multirow[b]{2}{*}{ Symptom } & \multicolumn{3}{|c|}{ Criteria } & \multirow[b]{2}{*}{ Change } \\
\hline & Rome I & Rome II & Rome III & \\
\hline Duration & $\begin{array}{l}\text { Two or more of the following for at least } \\
3 \text { months: }\end{array}$ & $\begin{array}{l}\text { At least } 12 \text { weeks, which need not be } \\
\text { consecutive, in the preceding } 12 \text { months } \\
\text { of two or more of the following: }\end{array}$ & $\begin{array}{l}\text { Two or more of the following for at least } \\
3 \text { months, with symptom(s) onset at least } \\
6 \text { months before diagnosis: }\end{array}$ & Yes \\
\hline Straining & $>25 \%$ of the time & $>25 \%$ of the time & During $25 \%$ of defecations & No \\
\hline Lumpy/hard stools & $>25 \%$ of the time & $>25 \%$ of the time & At least $25 \%$ of defecations & No \\
\hline Tenesmus & $\begin{array}{l}\text { Sensation of incomplete evacuation } \\
>25 \% \text { of the time }\end{array}$ & $\begin{array}{l}\text { Sensation of anorectal obstruction/ } \\
\text { blockage in }>25 \% \text { of defecations }\end{array}$ & $\begin{array}{l}\text { Sensation of incomplete evacuation in at } \\
\text { least } 25 \% \text { of defecations }\end{array}$ & Yes \\
\hline $\begin{array}{l}\text { Manoeuvres to } \\
\text { facilitate defecation }\end{array}$ & - & $\begin{array}{l}>25 \% \text { of defecations (eg, digital } \\
\text { evacuation, support of the pelvic floor) }\end{array}$ & $\begin{array}{l}\text { In at least } 25 \% \text { of defecations (eg, digital } \\
\text { evacuation, support of the pelvic floor) }\end{array}$ & Yes \\
\hline $\begin{array}{l}\text { Number of bowel } \\
\text { movements }\end{array}$ & $\leq 2$ per week & $<3$ per week & $<3$ per week & Yes \\
\hline Abdominal pain & Not required & - & - & No \\
\hline Loose stools & Not present & Not present & Rarely present without the use of laxatives & Yes \\
\hline Others & $\begin{array}{l}\text { Insufficient data for irritable bowel } \\
\text { syndrome. Criteria do not apply when } \\
\text { patient takes laxatives }\end{array}$ & $\begin{array}{l}\text { Insufficient data for irritable bowel } \\
\text { syndrome. Criteria do not apply when } \\
\text { patient takes laxatives }\end{array}$ & Insufficient criteria for laxatives & No \\
\hline
\end{tabular}

Adapted from the Rome Foundation website (www.romecriteria.org)

There are little data regarding the incidence of CC. In a populationbased study, Choung et al (19) found that the cumulative incidence of CC over a 12-year period (1998 to 2003) was $17.4 \%$. Interestingly, the cumulative incidence was age and sex related. Among those younger than 50 years of age at baseline, the incidence of CC differed according to sex (9.2\% in men versus $18.3 \%$ in women); however, in those older than 70 years of age, the incidence was found to be similar in men and women $(20.6 \%$ versus $25.0 \%$, respectively).

\section{DEMOGRAPHICS OF CC}

There is strong evidence that constipation occurs more frequently in women, with a female/male ratio ranging from 1.01 to $3.77(18,20)$. The exact mechanisms for this sex difference are not fully understood, but accumulating evidence points to female sex hormones $(21,22)$. Older data from a large US population-based, self-report survey (23) found a higher prevalence of constipation in women than men, affecting $20.8 \%$ and of $8.0 \%$ respondents, respectively. Similar results were found by the Epidemiology of Constipation (EPOC) study (7), in which $16 \%$ of women and $12 \%$ of men met symptom criteria for constipation, with no major differences between sex with respect to laxative use; $2.0 \%$ of women and $1.4 \%$ of men reported laxative use at least every other day. In a recent study, Talley et al (16) evaluated an age- and sex-stratified random sample of 1021 Olmsted County residents with a follow-up period of 12 to 20 months. Similar to earlier studies, women were more prone to constipation and reported infrequent stooling more often, manual disimpaction, and laxative or enema use. Men, on the other hand, reported prolonged defecation more often and the feeling of incomplete evacuation. A recent Canadian study (17) also showed that women were more likely than men to experience lower GI symptoms: $60 \%$ of women reported constipation at least weekly and more than $90 \%$ monthly. Furthermore, more than $60 \%$ of women had been living with these symptoms for more than 10 years.

There is a strong association between age and FGIDs such as IBS or functional constipation, with most of the younger patients having IBS and those older than 64 years of age fulfilling criteria for functional constipation (11). CC increases with advancing age, particularly after 65 years of age $(14,18)$. Several studies investigating constipation in elderly patients, mainly using self-reported constipation, found a prevalence rate of between $12.5 \%$ and $30 \%$ (24-27). As expected, when applying self-reported or Rome criteria-based constipation, Talley et al (28) observed different rates ( $31.9 \%$ and $24.4 \%$, respectively).

There is no consensus regarding the relationship between race and constipation. Several studies have reported an increased prevalence of constipation in non-Caucasian subjects, with a ratio ranging from 1.13 to $2.89(3,5,18)$. In contrast, a recent National Health and Wellness Survey (29) found that patients with CC $(n=1430)$ were mostly Caucasian (78\%).

Using different methodologies, a few studies have evaluated the relationship between socioeconomic status and constipation. Lower socioeconomic status, rural residency, cold climate (30) and lower education (18) appear to be risk factors for constipation. In a systematic review (31), subjects with lower incomes had significantly higher rates of constipation than their wealthier counterparts.

\section{CONSTIPATION AND USE OF HEALTH CARE}

Despite the fact that constipation is a very common problem, only a small proportion of symptomatic patients seek medical care. A Canadian study (14) found that only $34.0 \%$ of subjects with selfreported constipation consulted a physician, and $34.3 \%$ of these individuals used laxatives. Using the Rome II criteria, only $26.3 \%$ of patients reported a physician visit or the use of prescribed or OTC medication. There was a significant correlation between the presence of severe symptoms and health care use. Previous use of constipation medications and antidepressants, as well as a history of self-reported constipation, were predictors of health care seeking. Women were almost twice more likely than men to seek medical care for selfreported constipation. Of note, when patients were asked about the reasons for not seeking health care, $36 \%$ did not consider the condition as severe, and $22 \%$ did not consider themselves to be constipated. These data support previous studies suggesting that self-reported constipation does not reflect its true prevalence.

Irvine et al (20) reported that health care seeking (ever having visited a doctor) for constipation occurred in $28.9 \%$ of the 444 subjects who self-reported constipation in the previous 12 months, and occurred more frequently in females and elderly patients (20). Patients with constipation also reported seeing nonphysician health care professionals including pharmacists $(7.2 \%)$, herbalists $(2.3 \%)$, home care nurses $(1.8 \%)$ or other professionals $(3.2 \%)$. One-third of patients were consuming fibre supplements, up to $20 \%$ used laxatives and less than $10 \%$ used stool softeners in the previous three months. In another study including 200 patients with self-reported constipation (11), $86.5 \%$ of patients used medication, including herbal or homeopathic remedies, to treat their constipation for more than one year. Similar data were obtained in patients with lower GI dysmotility (17). In both studies, only a few subjects reported satisfaction with their current treatment, demonstrating the need for more efficient therapies, better prescribing habits and/or improved patient compliance. 
TABLE 2

Constipation-specific instruments for assessment of quality of life

\begin{tabular}{lcccc}
\hline Instrument & Items, n/score & Concepts involved & Dimensions evaluated & Reference \\
\hline PAC-QoL & 28 & $\begin{array}{c}\text { Worries and concerns, physical discomfort; psychosocial discomfort } \\
\text { satisfaction, overall score }\end{array}$ & Well-being in five dimensions \\
EBSQ & 49 & $\begin{array}{c}\text { Abdominal pain, bowel function, upper gastrointestinal complaints, } \\
\text { doctor visits, daily activities, health habits }\end{array}$ & $\begin{array}{c}\text { General gastrointestinal symptoms in } \\
\text { elderly patients and their relation to } \\
\text { daily activities }\end{array}$ \\
CVE-20 (Spanish) & 20 & Emotional, general physical, rectal physical and social domains & Health states in different perspectives & 56 \\
\hline
\end{tabular}

CVE-20 Quality of life specific questionnaire for constipated patients; EBSQ Elderly Bowel Symptom Questionnaire; PAC-QoL Patient Assessment of Constipation Quality of Life questionnaire

\section{QoL IN PATIENTS WITH CC}

Once an FGID is diagnosed, most physicians tend to minimize the situation, while patients' concerns toward their disorder increase. Most patients do not understand their situation and suffer from social isolation because eating may precipitate symptoms. Patients are often fearful that their symptoms will relapse, and feel frustrated due to the lack of effective therapies and empathy from family and coworkers (32). In chronic conditions, such as functional constipation, patients are more concerned about their QoL and disability rather than longevity (33). The measurement of health-related QoL (HRQoL) may be used in individual patient management or, more commonly, to provide insight into the typical impact of one or more related conditions within a defined group of patients (31). Apart from general questionnaires, such as the Short-Form-36 (SF-36), several constipationspecific instruments have been developed (Table 2). One of the most used tools is the Patient Assessment of Constipation - Quality of Life questionnaire (PAC-QoL), which has been shown to be internally consistent, reproducible, valid and responsive to improvements over time (34). This makes the tool especially valuable for tracking individual patients longitudinally, but of limited value when comparing a group of patients with constipation versus patients with IBS. In elderly patients with constipation, the Elderly Bowel Symptom Questionnaire (EBSQ) may be more appropriate (35). If the intention is to compare the impact of constipation with a non-GI problem, a generic HRQoL tool is required - some of the most commonly used being version 2 of the SF-36 (SF-36v2) (36), the Health Utilities Index mark 3 (HUI3) (37) or the European Quality of Life-5 Dimensions questionnaire (EQ-5D) (38).

Several studies have demonstrated reductions in HRQOL measurements as well as general well-being in patients with FGIDs, including CC, compared with healthy controls, particularly those seen in referral settings (39). Several population based-studies showed that constipation is physically and mentally troublesome for many patients $(11,40)$, and can interfere with daily living and well-being, especially in older age groups (41).

Irvine et al (20) investigated self-reported constipation in a Canadian population using the Rome II definition and found decreased mental and physical subscores on the SF-36 in patients with FGIDs compared with controls. Subjects with self-reported constipation had the lowest mean scores in almost all domains among the groups investigated. Both self-reported and Rome II functional constipation subjects had significantly worse scores than the normal Canadian population. Similarly, a large community-based study conducted with employees of the Veteran's Affairs health care system (42) showed that patients with functional constipation (Rome I) had lower QoL scores than nonconstipated persons and these differences persisted even when subjects with constipation associated with IBS were excluded from the analysis. A recent systematic review evaluating 10 community-and hospital-based studies using SF-36, SF-12 and Psychological Well-Being (PGWB) questionnaire (31), confirmed that patients with $\mathrm{CC}$ have a significantly impaired HRQoL (31). The scores of the community patient population were comparable with that in patients with organic diseases such as inflammatory bowel disease, diabetes, chronic allergy or rheumatological conditions. Similarly, the recent results from the National Health and Wellness Survey (29) showed that patients with CC reported significantly lower levels of HRQoL than propensity score-matched controls (in both physical and mental component scores).

Differences exist in how patients with CC perceive their disease. Using the PGWB questionnaire in patients with severe CC, Glia and Lindberg (43) showed that patients with slow-transit constipation had higher scores (ie, better well-being) than those with normal-transit constipation, and those with fewer than three stools per week scored higher than those with more frequent bowel movements.

While it is clearly useful to understand the impact of constipation on individuals and groups of patients, these data are of great value when a treatment is shown to improve QoL. This has been investigated in several studies that have demonstrated that $\mathrm{QoL}$ improves after relief of constipation (44-47). A recent study by Quigley et al (44) evaluated the effect of the novel prokinetic prucalopride on PAC-QoL in patients with CC. A 12-week treatment using two regimens of prucalopride significantly improved $\mathrm{QoL}$ and satisfaction with bowel function compared with placebo.

Traditionally, FGIDs were not considered to be associated with an increase in mortality. However, recent data from Statistics Canada (40) has shown for the first time that a relationship between death and constipation exists. Chang et al (48) also reported increased mortality associated with CC in the US population, although this appeared to be due to coexisting serious diseases rather than constipation per se (49). The same authors have recently published a population-based historical cohort study of randomly selected subjects from Olmsted County (50) concluding that, in contrast to other FGIDs, subjects with $\mathrm{CC}$ are at an increased risk of poorer survival compared with those without constipation ( $73 \%$ versus $85 \%$, respectively). Because the authors found no association between symptoms of constipation and colorectal cancer, or any other GI malignancy, they concluded that constipation was a surrogate for general health status and was reflective of underlying comorbidities.

\section{ECONOMIC IMPACT OF CC}

It is well established that FGIDs have a significant impact on health care use, resulting in tremendous economic burden. Extrapolating from available information, and conservatively assuming that 2.5 million individuals with constipation undergo evaluation annually, Chang et al (50) calculated that testing in constipation costs $\$ 6.9$ billion, aside from any treatment costs. Another study estimated that $85 \%$ of physician visits for constipation resulted in a prescription, suggesting that drug costs are responsible for a significant proportion of expenditures (51). Considering that constipation-related symptoms account for more than 2.5 million office visits in North America, it is estimated that more than $\$ 500$ million is spent on laxatives each year $(52,53)$.

In a recent study, Nyrop et al (54) reported a mean total annual cost of $\$ 7,522$ for health care provided to each constipated patient. Surprisingly, these costs were higher than those for patients with IBS. The authors did not find any differences between males and females in health care costs; however, similar to previous reports, women were 
found to use more nonprescription and alternative medicine treatments. Furthermore, education had an intriguing, paradoxical effect on health care costs: college-educated subjects incurred significantly lower health care costs through their insurance program, but spent significantly more on nonprescription and alternative medicine treatments. This may be related to a reduced willingness of college graduates to take time off from work to visit a medical clinic, and greater economic resources enabling them to take advantage of nontraditional treatments.

The burden of CC also extends to a loss in work productivity. Employment and social activities are affected in patients with CC: almost 30\% believe that they were less productive at work or at school, $13 \%$ missed work or school days, and nearly $10 \%$ were late or had to leave work or school because of their symptoms (17). Others found that among CC sufferers who were employed or attended school, there was a loss of 2.4 productive days per month due to their symptoms (55). A recent National Health and Wellness Survey also reported a significantly greater percentage of work time missed due to health (9.08\% versus $5.20 \%$ in controls) and greater impairment during daily activities (46.58\% versus $33.90 \%$ in controls) (29). The global impact of absenteeism has been estimated - a mean period of work absence of 0.4 days/year is equivalent to 13.7 million days of restricted activity in the US each year (31).

\section{CONCLUSIONS}

By any definition - self-reported or using the Rome criteria - CC is an important component of clinical gastroenterology practice worldwide. Constipation symptoms significantly impacts patients' QoL and the country's economy. CC is the fourth-ranked cause of consultation for GI disorders, and the total health care use burden associated with this condition is remarkably high (32). Patients who believe they are constipated are likely to seek treatment either by use of OTC products or by visiting their physicians to request a prescription. As evidenced by the hundreds of millions of dollars spent per year on OTC laxatives alone, the health care costs of constipation are significant, which surprisingly, surpass the costs for IBS (54). Given the fact that constipation occurs more frequently in elderly patients and that life expectancy is increasing, we can expect an increase in the prevalence of constipation in the years to come, with the associated impact on QoL, and the increased social and economic burden.

CONFLICTS OF INTEREST: Dr P Bercik has received grant support from Nestle Switzerland and is a member of the Advisory Board for Janssen Canada. MI Pinto Sanchez has no financial disclosures or conflicts of interest to declare.

\section{REFERENCES}

1. Chang JY, Locke GR III, McNally MA, et al. Impact of functional gastrointestinal disorders on survival in the community. Am J Gastroenterol 2010;105:822-32.

2. Longstreth GF, Thompson WG, Chey WD, et al. Functional bowel disorders. Gastroenterology 2006;130:1480-91 .

3. American College of Gastroenterology Chronic Constipation Task Force. An evidence-based approach to the management of chronic constipation in North America. Am J Gastroenterol 2005;100(Suppl 1):S1-4 .

4. Talley N. Definition, epidemiology and impact of chronic constipation. Rev Gastroenterol Disord 2004;4(Suppl 2):S3-S10.

5. Sandler R, Drossman DA. Bowel habits in young adults not seeking health care. Dig Dis Sci 1987;32:841-5.

6. Wald A. Diagnosis of constipation in primary and secondary care. Rev Gastroenterol Disord 2004;4(Suppl 2):S28-S33.

7. Stewart WF, Liberman JN, Sandler RS, et al. Epidemiology of constipation (EPOC) study in the United States: Relation of clinical subtypes to sociodemographic features. Am J Gastroenterol 1999;94:3530-40.

8. Ruben BD. Public perceptions of digestive health and disease: Survey findings and communications implications. Pract Gastroenterol 1986;10:35-42.

9. Trinkley KE, Porter K, Nahata MC, Prescribing patterns for the outpatient treatment of constipation in the United States. Dig Dis Sci 2010;55:3514-20.

10. Faigel DO. A clinical approach to constipation. Clin Cornerstone 2002;4:11-21.

11. Heaton KW, Radvan J, Cripps H, et al. Defecation frequency and timing, and stool form in the general population: A prospective study. Gut 1992;33:818-24.

12. Ferrazzi S, Thompson GW, Irvine EJ, Pare P, Rance L. Diagnosis of constipation in family practice. Can J Gastroenterol 2002;16:159-64.

13. Harris LA, Hansel S, DiBaise J, Crowell MD. Irritable bowel syndrome and chronic constipation: Emerging drugs, devices, and surgical treatments. Curr Gastroenterol Rep 2006;8:282-90.

14. Pare P, Ferrazzi S, Thompson WG, et al. An epidemiological survey of constipation in Canada: Definitions, rates, demographics, and predictors of health care seeking. Am J Gastroenterol 2001;96:3130-7.

15. Drossman DA, Li Z, Andruzzi E, et al. U.S. householder survey of functional gastrointestinal disorders. Prevalence, sociodemography and health impact. Dig Dis Sci 1993;38:1569-80.

16. Talley NJ, Weaver AL, Zinsmeister AR, et al. Functional constipation, and outlet delay. A population-based study. Gastroenterology 1993;105:781-90.
17. Hunt R, Dhaliwal S, Tougas G, et al. Prevalence, impact and attitudes toward lower gastrointestinal dysmotility and sensory symptoms and their treatment in Canada: A descriptive study. Can J Gastroenterol 2007;21:31-7.

18. Higgins P, Johanson JF. Epidemiology of constipation in North America: A systematic review. Am J Gastroenterol 2004;99:750-9.

19. Choung RS, Locke GR, Schleck CD, et al. Cumulative incidence of chronic constipation: A population based study 1988-2003. Aliment Pharm Ther 2007;26:1521-8.

20. Irvine EJ, Ferrazzi S, Pare P, et al. Health-related quality of life in functional GI disorders: Focus on constipation and resource utilization. Am J Gastroenterol 2002;97:1986-93.

21. Triadafilopoulos G, Finlayson M, Grellet C. Bowel dysfunction in postmenopausal women. Women Health 1998;27:55-66.

22. Gonenne J, Esfandyari T, Camilleri M. Effect of female sex hormone supplementation and withdrawal on gastrointestinal and colonic transit in postmenopausal women. Neurogastroenterol Motil 2006;18:911-8.

23. Everhart JE, Go VL, Johannes RS, et al. A longitudinal survey of self-reported bowel habits in the United States. Dig Dis Sci 1989;34:1153-62.

24. Robson KM, Kiely DK, Lembo T. Development of constipation in nursing home residents. Dis Colon Rectum 2000;43:940-3.

25. Thompson WG, Heaton KW. Functional bowel disorders in apparently healthy people. Gastroenterology 1980;79:283-8.

26. Whitehead WE, Drinkwater D, Cheskin LJ, et al. Constipation in the elderly living at home. Definition, prevalence, and relationship to lifestyle and health status. J Am Geriatr Soc 1989;37:423-9.

27. Harari D, Gurwitz JH, Avorn J, Choodnovskiy I, Minaker KL. Constipation: Assessment and management in an institutionalized elderly population. J Am Geriatr Soc 1994;42:947-52.

28. Talley NJ, Fleming KC, Evans JM, et al. Constipation in an elderly community: A study of prevalence and potential risk factors. Am J Gastroenterol 1996;91:19-25.

29. Sun SX, Dibonaventura M, Purayidathil FW, Wagner JS, Dabbous O, Mody R. Impact of chronic constipation on health-related quality of life, work productivity, and healthcare resource use: An analysis of the National Health and Wellness Survey. Dig Dis Sci 2011 Mar 6 (Epub ahead of print).

30. Johanson JF. Geographic distribution of constipation in the United States. Am J Gastroenterol 1998;93:181-91.

31. Belsey J, Greenfield S, Candy D, Geraint M. Systematic review: Impact of constipation on quality of life in adults and children Aliment Pharmacol Ther 2010;31:938-49. 
32. Shaheen NJ, Hansen RA, Morgan DR, et al. The burden of gastrointestinal and liver diseases 2006. Am J Gastroenterol 2006;101:2128-30.

33. Locke GR III, Pemberton JH, Phillips SF. AGA technical review on constipation. American Gastroenterology Association. Gastroenterology 2000;119:1766-78.

34. Marquis P, De La LC, Dubois D, McDermott A, Chassany O. Development and validation of the Patient Assessment of Constipation Quality of Life questionnaire. Scand J Gastroenterol 2005;40:540-51.

35. O'Keefe EA, Talley NJ, Tangalos EG, Zinsmeister AR. A bowel symptom questionnaire for the elderly. J Gerontol 1992;47:M116-21.

36. McHorney CA, Ware JE Jr, Raczek AE. The MOS 36-Item ShortForm Health Survey (SF-36): II. Psychometric and clinical tests of validity in measuring physical and mental health constructs. Med Care 1993;31:247-63.

37. Feeny D, Furlong W, Boyle M, Torrance GW. Multi-attribute health status classification systems. Health Utilities Index. Pharmacoeconomics 1995;7:490-502.

38. Brazier J, Jones N, Kind P. Testing the validity of the Euroqol and comparing it with the SF-36 health survey questionnaire. Qual Life Res 1993;2:169-80.

39. Chang L. Review article: Epidemiology and quality of life in functional gastrointestinal disorders. Aliment Pharmacol Ther 2004;20(Suppl 7):31-9.

40. Statistics Canada. Deaths, by cause, Chapter XI: Diseases of the digestive system (K00 to K93), age group and sex, Canada, 2000 to $2007<$ http://www5.statcan.gc.ca/cansim/a03> (Accessed on July 4, 2011).

41. O'Keefe EA, Talley NJ, Zinsmeister AR, et al. Bowel disorders impair functional status and quality of life in the elderly: A population-based study. J Gerontol 1995;50:184-9.

42. Tuteja AK, Talley NJ, Joos SK, et al. Is constipation associated with decreased physical activity in normally active subjects? Am J Gastroenterol 2005;100:124-9.

43. Glia A, Lindberg G. Quality of life in patients with different types of functional constipation. Scand J Gastroenterol 1997;32:1083-9.
44. Quigley EM, Vandeplassche L, Kerstens R, et al. Clinical trial: The efficacy, impact on quality of life, and safety and tolerability of prucalopride in severe chronic constipation - a 12-week, randomized, double-blind, placebo-controlled study. Aliment Pharmacol Ther 2009;29:315-28

45. On Chan AO, Mo HW, Leung G, et al. Efficacy of tegaserod for functional constipation in Chinese subjects: A randomized doubleblind controlled trial in a single centre. Aliment Pharmacol Ther 2007;25:463-9.

46. Charach G, Greenstein A, Rabinovich P, Groskopf I, Weintraub M. Alleviating constipation in the elderly improves lower urinary tract symptoms. Gerontology 2001;47:72-6.

47. Nyam DC, Pemberton JH, Ilstrup DM, Rath DM. Long-term results of surgery for chronic constipation. Dis Colon Rectum 1997;40:273-9.

48. Chang JY, Locke GR, Schleck CD, et al. Chronic constipation is associated with poorer survival in a US population. Am J Gastroenterol 2006;101:S484.

49. Talley N. Functional gastrointestinal disorders as a public health problem. Neurogastroenterol Motil 2008;20(Suppl 1):121-9.

50. Chang JY, Locke GR III, McNally MA, et al. Impact of functional gastrointestinal disorders on survival in the community. Am J Gastroenterol 2010;105:822-3.

51. Sonnenberg A, Koch TR. Epidemiology of constipation in the United States. Dis Colon Rect 1989;32:1-8.

52. Crowell M, Harries LA, Lunsford TN, Dibiase JK. Emerging drugs for chronic constipation. Expert Opin Emerg Drugs 2009; 14:493-504.

53. Johanson JF, Sonnenberg A, Koch TR. Clinical epidemiology of chronic constipation. J Clin Gastroenterol 1989;11:525-36.

54. Nyrop KA, Palsson OS, Levy RL, et al. Costs of health care for irritable bowel syndrome, chronic constipation, functional diarrhea and functional abdominal pain. Aliment Pharmacol Ther 2007;26:237-48

55. Johanson JF, Kralstein J. Chronic constipation: A survey of the patient perspective. Aliment Pharmacol Ther 2007;25:599-608.

56. Perona M, Mearin F, Guilera M, et al; Study group on functional gastrointestinal disorders from the Spanish Association of Gastroenteroloy (AEG). Quality of life specific questionnaire for constipated patients: Development and validation of CVE-20. Med Clin (Barc) 2008;131:371-7. 


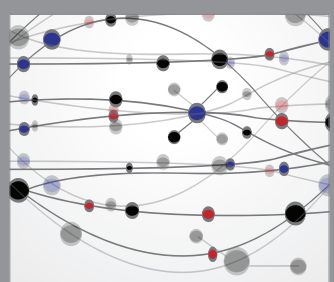

The Scientific World Journal
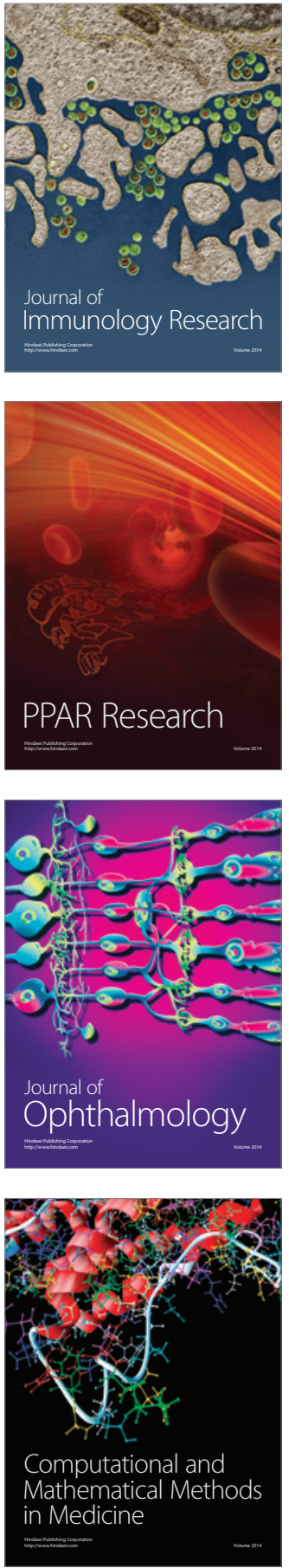

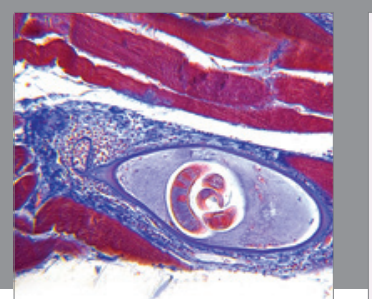

Gastroenterology Research and Practice

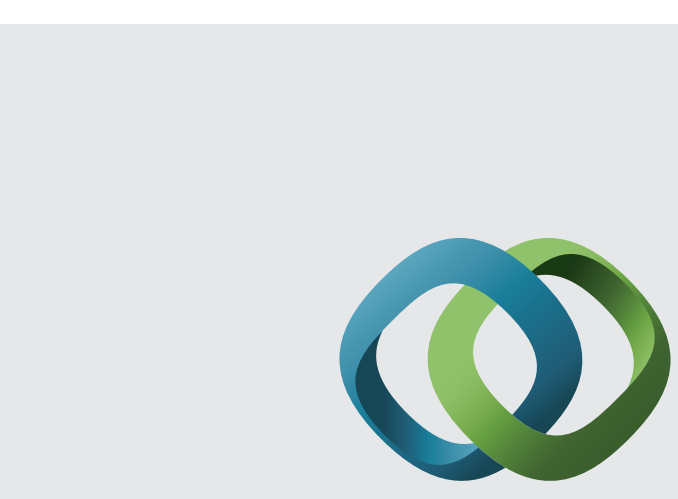

\section{Hindawi}

Submit your manuscripts at

http://www.hindawi.com
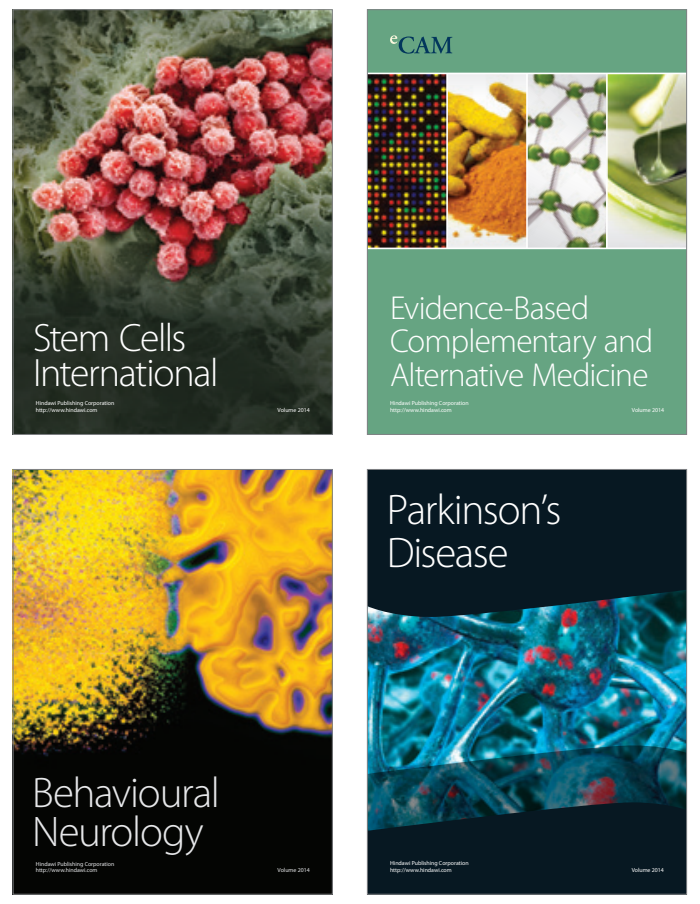
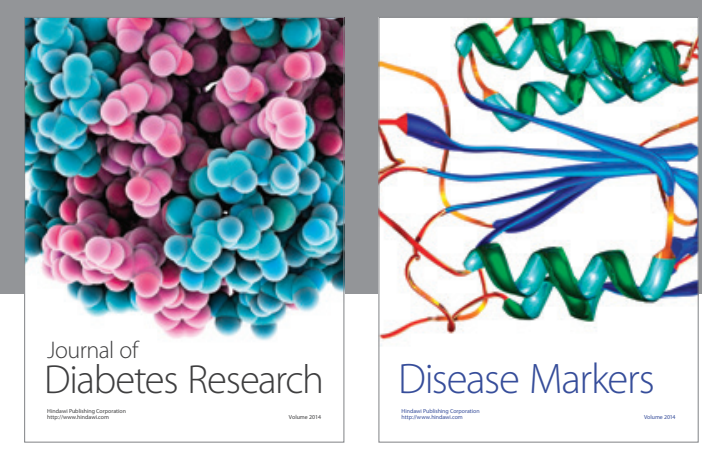

Disease Markers
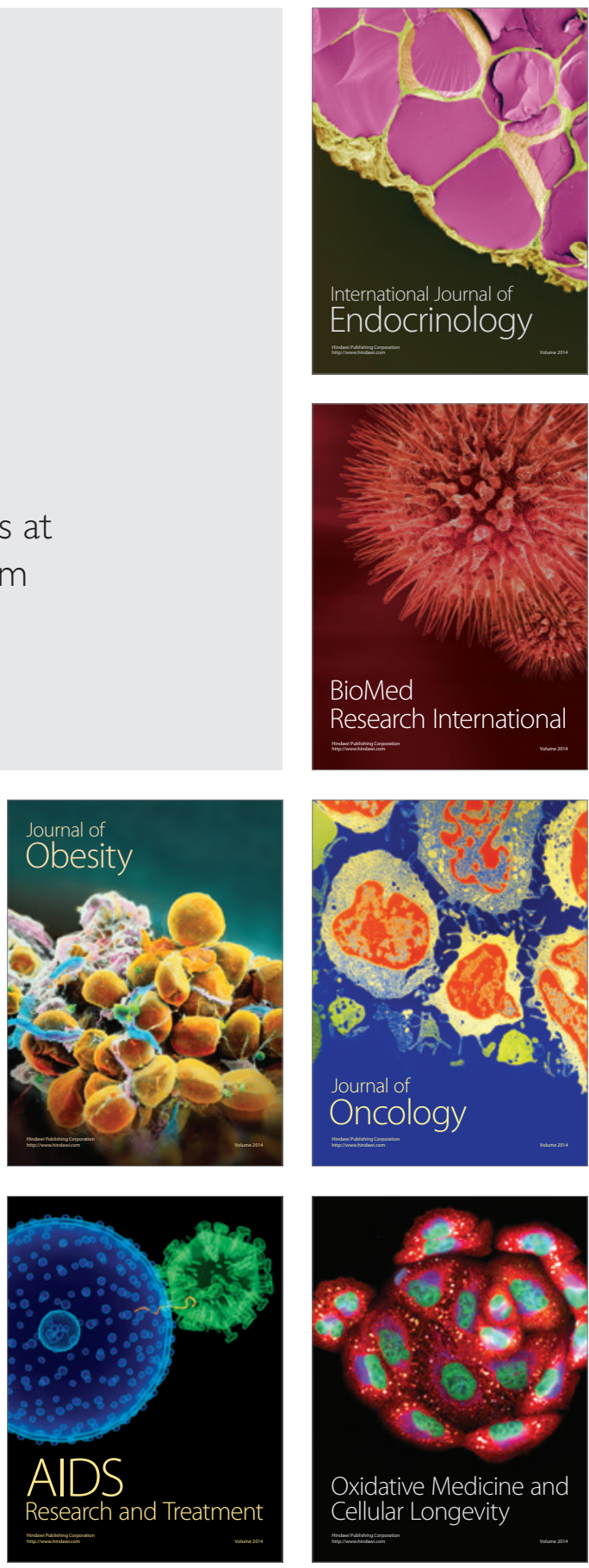